\title{
Exploring the binding properties and structural stability of an opsin in the chytrid Spizellomyces punctatus using comparative and molecular modeling
}

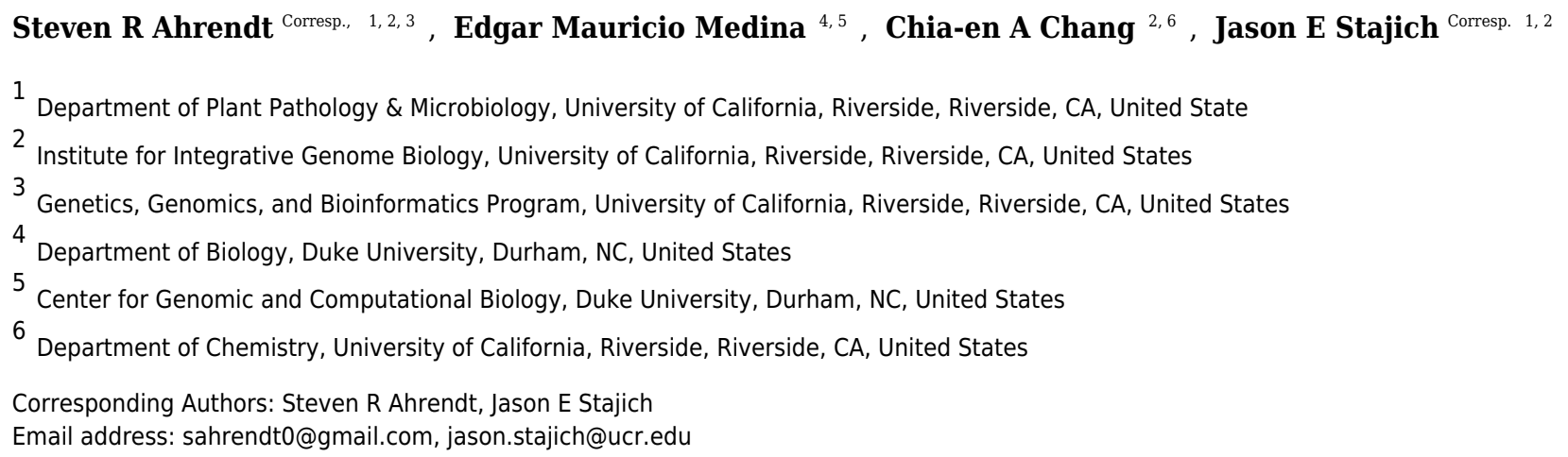

Background. Opsin proteins are seven transmembrane receptor proteins which detect light. Opsins can be classified into two types and share little sequence identity: type 1, typically found in bacteria, and type 2, primarily characterized in metazoa. The type 2 opsins (Rhodopsins) are a subfamily of G-protein coupled receptors (GPCRs), a large and diverse class of seven transmembrane proteins and are generally restricted to metazoan lineages. Fungi use light receptors including opsins to sense the environment and transduce signals for developmental or metabolic changes. Opsins characterized in the Dikarya (Ascomycetes and Basidiomycetes) are of the type 1 bacteriorhodopsin family but the early diverging fungal lineages have not been as well surveyed. We identified by sequence similarity a rhodopsin-like GPCR in genomes of early diverging chytrids and examined the structural characteristics of this protein to assess its likelihood to be homologous to animal rhodopsins and bind similar chromophores.

Methods. We used template-based structure modeling, automated ligand docking, and molecular modeling to assess the structural and binding properties of an identified opsin-like protein found in Spizellomyces punctatus, a unicellular, flagellated species belonging to Chytridiomycota, one of the earliest diverging fungal lineages. We tested if sequence and inferred structure were consistent with a solved crystal structure of a type 2 rhodopsin from the squid Todarodes pacificus.

Results. Our results indicate that the Spizellomyces opsin has structural characteristics consistent with functional animal type 2 rhodopsins and is capable of maintaining a stable structure when associated with the retinaldehyde chromophore, specifically the 9-cis-retinal isomer. Together, these results support further the homology of Spizellomyces opsins to animal type 2 rhodopsins.

Discussion. This represents the first test of structure/function relationship of a type 2 rhodopsin identified in early branching fungal lineages, and provides a foundation for future work exploring pathways and components of photoreception in early fungi. 
1 Exploring the binding properties and structural stability of an opsin in the chytrid

2 Spizellomyces punctatus using comparative and molecular modeling

3

4 Steven R. Ahrendt ${ }^{1,2,3}{ }^{\dagger}$, Edgar M. Medina ${ }^{4,5}$, Chia-en A. Chang ${ }^{2,6}$, and Jason E. Stajich ${ }^{1,2 *}$

5

$6 \quad{ }^{1}$ Department of Plant Pathology \& Microbiology

7 University of California-Riverside

8 Riverside, California 92521

9

${ }^{2}$ Institute for Integrative Genome Biology

11 University of California-Riverside

12 Riverside, California 92521

13

$14{ }^{3}$ Graduate program in Genetics, Genomics, and Bioinformatics

15 University of California-Riverside

16 Riverside, California 92521

17

$18 \quad{ }^{4}$ Department of Biology

19 Duke University

20 Durham, North Carolina 27708

21

$22{ }^{5}$ Center for Genomic and Computational Biology

23 Duke University

24 Durham, North Carolina, 27710

25

${ }^{6}$ Department of Chemistry,

27 University of California-Riverside

28 Riverside, California 92521

29

$30{ }^{\dagger}$ Present address:

31 DOE Joint Genome Institute,

32 Walnut Creek, CA 94598

33

$34{ }^{*}$ Corresponding Author: Jason E. Stajich jason.stajich@ucr.edu 35 
36

37

38

39

40

41

42

43

44

45

46

47

48

49

50

51

52

53

54

55

56

57

58

59

60

61

62

63

64

65

66

67

68

69

70

71

72

73

74

75

\section{Abstract}

Background. Opsin proteins are seven transmembrane receptor proteins which detect light. Opsins can be classified into two types and share little sequence identity: type 1, typically found in bacteria, and type 2, primarily characterized in metazoa. The type 2 opsins (Rhodopsins) are a subfamily of G-protein coupled receptors (GPCRs), a large and diverse class of seven transmembrane proteins and are generally restricted to metazoan lineages. Fungi use light receptors including opsins to sense the environment and transduce signals for developmental or metabolic changes. Opsins characterized in the Dikarya (Ascomycetes and Basidiomycetes) are of the type 1 bacteriorhodopsin family but the early diverging fungal lineages have not been as well surveyed. We identified by sequence similarity a rhodopsin-like GPCR in genomes of early diverging chytrids and examined the structural characteristics of this protein to assess its likelihood to be homologous to animal rhodopsins and bind similar chromophores.

Methods. We used template-based structure modeling, automated ligand docking, and molecular dynamics to assess the structural and binding properties of an identified opsin-like protein found in Spizellomyces punctatus, a unicellular, flagellated species belonging to Chytridiomycota, one of the earliest diverging fungal lineages. We tested if sequence and inferred structure were consistent with a solved crystal structure of a type 2 rhodopsin from the squid Todarodes pacificus.

Results. Our results indicate that the Spizellomyces opsin has structural characteristics consistent with functional animal type 2 rhodopsins and is capable of maintaining a stable structure when associated with the retinaldehyde chromophore, specifically the 9-cis-retinal isomer. Together, these results support further the homology of Spizellomyces opsins to animal type 2 rhodopsins.

Discussion. This represents the first test of structure/function relationship of a type 2 rhodopsin identified in early branching fungal lineages, and provides a foundation for future work exploring pathways and components of photoreception in early fungi.

Keywords: Chytrid; Opsin; Homology Modeling; Light receptor; Protein structure; GPCR Early diverging fungi; Evolution; Mycology

\section{Introduction}

An organism experiences a multitude of environmental stimuli including chemical, gravity, the Earth's magnetic field, pressure, and light. The biochemical ability to appropriately process and respond to these signals is a complex and involved task, and understanding the molecular mechanisms of these responses is an ongoing scientific challenge. The presence or absence of light is perhaps one of the easiest sources of stimuli to comprehend and observe. The daily cycles of sunlight due to the rotation of the planet has had a profound influence on the 
development of life that it comes as no surprise to find some form of photoreception in nearly every organism on the planet. The widespread occurrence of such an ability, however varied in its implementation, speaks to its importance during the earliest stages of development of life.

In Fungi, there are several classes of proteins capable of photoreception that function by different mechanisms of action and have varied structures, sensitivities, and specializations. These include blue light responsive white-collar complex, VIVID and cryptochrome photoreceptors, red light responsive phytochromes, and multi-wavelength light responsive opsins (Idnurm, Verma, \& Corrochano, 2010). The opsins are a large class of seven-transmembrane proteins which bind retinylidene compounds required for photoreception and can be subdivided into Types 1 or 2 based on phylogenetic history, sequence similarity, and function. The classes share some characteristics in structure (i.e. seven helical transmembrane domains) and mechanism of activation (i.e. photoisomerization of a retinaldehyde chromophore) but have distinct evolutionary histories (Spudich et al., 2000). Opsins are part of the large G-protein coupled receptor (GPCR) superfamily, which has more than 800 distinct described members in humans (Lagerström \& Schiöth, 2008). GPCR proteins share a similar architecture: seven membrane-spanning helical regions connected by three intracellular and three extracellular loop regions. The cytoplasmic region of the GPCR interacts with heterotrimeric $G$ proteins found on the intracellular side of the plasma membrane, which in turn function in signal transduction (Neves, Ram, \& Ivengar, 2002). Of the five major GPCR families, the Class-A family, comprising the opsins, various neurotransmitters, and hormone receptors, is by far the largest with approximately 700 proteins classified into four subfamilies (Katritch, Cherezov, \& Stevens, 2013).

The "Type 2 rhodopsins" represent a small subgroup of the opsin subfamily of Class-A GPCRs. Unlike other members of this class, they are activated by the interaction between a single photon of light and a covalently bound chromophore. A functional rhodopsin (rhodopsin pigment) is generated when an opsin apoprotein forms a covalent bond with a retinaldehyde chromophore via a Schiff-base linkage at a conserved lysine residue. While 11-cis-retinal is the most common chromophore observed in vertebrates and invertebrates, additional types are also found in nature. For example, 3,4-dehydroretinal is observed in fish, amphibians, and reptiles. Switching between the 11-cis- and 3,4-dehydro- chromophores can be employed as a light adaptation strategy in certain freshwater fish (Shichida \& Matsuyama 2009). 3-hydroxyretinal is found in insects, while 4-hydroxyretinal is observed in the firefly squid. In addition to the 11-cisconformation, retinal can adopt a number of different isomers, including all-trans-, 13-cis-, and 9-cis- (Shichida \& Matsuyama 2009). Previous studies using hybrid quantum mechanics/molecular mechanics $(\mathrm{QM} / \mathrm{MM})$ simulations suggest that the 11-cis-retinal isomer has been evolutionarily selected as the optimal chromophore due to the energetic stability of the resulting chromophore-opsin pigment (Sekharan \& Morokuma, 2011).

Activation of the rhodopsin occurs through the photoisomerization of 11-cis-retinal to alltrans-retinal, which causes a conformational change in the protein structure of the receptor. Alternatively, the ion transporter rhodopsins (part of the "Type 1 opsins") are activated by the 
116 photoisomerization of all-trans-retinal to 13-cis-retinal. These function as membrane channels 117 and are typically used for light-driven membrane depolarization via proton or chloride ion 118 pumping. Examples of this group can be found in bacteria, archaea, and eukaryotes, and include 119 the bacterial sensory rhodopsins, channelrhodopsins, bacteriorhodopsins, halorhodopsins, and

120

121

122

123

124

125

126

127

128

129

130

131

132

133

134

135

136

137

138

139

140

141

142

143

144

145

146

147

148

149

150

151

152

153

154

155 proteorhodopsins (Zhang et al., 2011). The nature of the evolutionary relationship between the two types of rhodopsin has not been definitively established and is currently the subject of discussion (Terakita, 2005; Shichida \& Matsuyama 2009; Becker et al., 2016; Devine, Theobald, \& Oprian, 2016).

There are at least three distinct phyla of early diverging fungi which are often referred to as "zoosporic fungi" or, more informally, "chytrids": the Cryptomycota, Chytridiomycota, and Blastocladiomycota (James et al., 2006; Stajich et al., 2009; Jones et al., 2011; James et al., 2013). These lineages share as a defining characteristic the presence of a flagellated life stage called a zoospore. Previous work has demonstrated that some species in these early diverging lineages are phototaxic. For example, the marine chytridiomycete Rhizophydium littoreum will respond to light at a variety of wavelengths, with the most rapid response occurring at $400 \mathrm{~nm}$ (Muehlstein, Amon, \& Leffler, 1987). While the evidence strongly suggests blue-light sensitivity, the researchers did not specifically characterize the active photoreceptor. Similarly, zoospores from the blastocladiomycete Allomyces reticulatus were determined not only to be phototactic, but also to possess visible, red-pigmented eyespots in which the photosensitive proteins are localized (Saranak \& Foster, 1997). Careful analysis determined that the action spectrum of the phototactic $A$. reticulatus zoospores peaks at $536+/-4 \mathrm{~nm}$, similar to that of the human green-sensitive cone. More recently, comprehensive work on the related blastocladiomycete Blastocladiella emersonii demonstrated that a type 1 rhodopsin is in part responsible for phototaxis in response to green light (522 nm) (Avelar et al. 2014).

An initial analysis of the chytrid Batrachochytrium dendrobatidis genome revealed a surprising finding of a GPCR protein with similarity to the rhodopsin superfamily. Searches of additional genomes of early diverging fungi, including the saprotrophic chytrid Spizellomyces punctatus, revealed the presence of rhodopsin-like proteins in multiple zoosporic fungal lineages. The availability of these examples of opsin homologs in the deeply diverging fungal lineages suggested the shared ancestry of these light sensing receptors and the presence of this pathway in the fungal-animal ancestor (Krishnan et al., 2012; Medina EM, unpublished data).

The growing availability of x-ray structures of different GPCRs has illustrated a strong similarity in overall topology (Katritch, Cherezov, \& Stevens, 2013). As a result, structural models built for various GPCRs have been successful in in silico screening of inhibitors or examining protein dynamics (Bermudez \& Wolber, 2015; Taddese et al., 2013; Ai \& Chang, 2012). Comparative modeling, also known as "homology modeling", is a computational method for building a structure for a protein of interest for which the structure is unknown. It is a template-based method which acts on the target's sequence similarity to proteins for which the structure has been experimentally verified (template) (Sali, 1995). It is distinct from ab initio or de novo modeling, which instead uses only the target sequence and free-energy minimization 
156 techniques (Bradley, Misura, \& Baker, 2005). Homology modeling works best when there is 157 high sequence identity between the target and template. Protein targets with sequence identity 158 levels $<30 \%$ with their template structure are often referred to as being in the "Twilight zone" of 159 homology modeling, where models generated from these alignments are not of the highest 160 quality (Chung \& Subbiah, 1996). Coupled with molecular dynamics (another computational

161

162

163

164

165

166

167

168

169

170

171

172

173

174

175

176

177

178

179

180

181

182

183

184

185

186

187

188

189

190

191

192

193

194

195 technique used to simulate interactions of complex molecules at the atomic level) and molecular docking (used to simulate protein-ligand interactions), homology modeling has multiple applications including structure-based drug discovery and investigations of protein dynamics.

The opsin-like proteins identified in the genomes of early diverging chytrid fungi are sufficiently similar to experimentally verified animal opsin structures for modeling and hypothesis testing about the potential ligand binding. We selected the Spizellomyces punctatus opsin-like GPCR for investigation as it possessed a conserved lysine residue suitable for retinal binding, unlike those in other chytrids. The target sequences and the rhodopsin homologs were modeled with Type 2 rhodopsin crystal structure templates made possible by the growing number of GPCR structures from the rhodopsin subfamily in the PDB (Katritch, Cherezov, \& Stevens, 2013). We generated a homology model for an opsin-like GPCR identified in the $S$.

punctatus and use it to explore the binding properties of retinal isomers, the functional chromophores in rhodopsin-mediated photosensing. Here we show that the S. punctatus opsin is structurally similar to functional animal type 2 rhodopsins and is stable when associated with a 9-cis-retinal chromophore.

\section{Materials \& Methods}

Sequence identification and homology modeling

Putative rhodopsin sequences in early diverging fungal lineages were identified based on sequence similarity to the Profile Hidden Markov model from the Pfam database (Finn et al., 2014), accession PF00001 ("7tm_1"). The HMM was searched against the predicted proteins from S. punctatus, B. dendrobatidis, A. macrogynus HMMER v3.0 (Eddy, 2011) using e-value cutoff 1e-10. Inspection of the protein sequence of the S. punctatus homolog revealed a putative truncation, which lead us to correct the gene model at locus SPPG_00350 by adding a missing cytosine in the genome at position 1041 of the locus. The discrepancy was identified using exonerate (Slater \& Birney, 2005) alignment of chytrid proteins to the genome to identify and correct this single deletion in the genome assembly (Supplemental file; https://github.com/stajichlab/chytropsin). The amended protein sequence SPPG_00350T0L was used for subsequent analyses. The $S$. punctatus protein structure model was constructed using the I-TASSER server with the provided GPCR specific library (Zhang, 2010). The normalized zscores, indicative of alignment quality, of the top ten threading templates used by I-TASSER are provided in Table S2. Additionally, manual correction of the K320 orientation was performed by energy minimization using the general Amber force field (GAFF) (Wang et al., 2004) in Avogadro (Hanwell et al., 2012) after automatic refinement with OpusROTA. The optimal 
196

197

198

199

200

201

202

203

204

205

206

207

208

209

210

211

212

213

214

215

216

217

218

219

220

221

222

223

224

225

226

227

228

229

230

231

232

233

234

235

model was selected using the I-TASSER provided "c-score", a confidence value based on the significance of threading template alignments. The rhodopsin crystal structure from Todarodes pacificus (PDBid 2Z73; Murakami \& Kouyama, 2008) was additionally selected for subsequent docking and molecular dynamics experiments. Stereochemical properties of both protein structures were validated using PROCHECK (v3.5) (Laskowski et al., 1993; Wiederstein \& Sippl, 2007), ProQM (Ray, Lindahl, \& Wallner, 2010), and Verify3D (Lüthy, Bowie, \& Eisenberg, 1992). The S. punctatus homology model structure file is available on Github at http://github.com/stajichlab/chytropsin/.

\section{Docking and Molecular dynamics (MD)}

Automated protein-ligand docking was accomplished using Autodock 4 (Morris et al., 2009) and implementing a Lamarckian genetic algorithm approach for calculating the minimum free energy of binding of small molecules. Small molecule files were obtained from PubChem (Bolton et al., 2008) for the following isomers of retinal: 11-cis (A1), all-trans, 9-cis, 13-cis, 3,4dehydro (A2), 3-hydroxy (A3), and 4-hydroxy (A4) used in the covalent docking screen. A covalent linkage was formed by manually specifying the presence of a bond between the terminal carbon atom in retinal and terminal nitrogen atom in the lysine side chain. The specific lysine predicted to be involved in Schiff-base linkage with the chromophore was inferred through multiple sequence alignment.

The dynamics of both the Todarodes and Spizellomyces rhodopsin complexes were investigated using all-atom molecular dynamics simulations with the Amber14 suite of programs (Case et al., 2015). Due to the computational expense of an explicit solvation model for simulating water molecules, an implicit solvation model (Onufriev, Bashford, \& Case, 2000) (modified from the generalized Born solvation model (Bashford \& Case, 2000)) was used in AMBER with the $i g b=2$ flag. The all atom force-field ff14SB (Hornak et al., 2006) was used as implemented in AMBER14, and GAFF was implemented for the ligand. Additionally, in order to mimic a membrane in which the protein would be found in vivo, all residues belonging to the transmembrane helices, except those within the binding pocket, were restricted using the restraint flag. Initial minimization was performed for $1 \mathrm{~ns}$, followed by three NVT equilibration steps for $50 \mathrm{ps}$ progressing from $200 \mathrm{~K}$ to $250 \mathrm{~K}$ to $298 \mathrm{~K}$. The final production simulation was run for $100 \mathrm{~ns}$ at $298 \mathrm{~K}$. For comparison, the photoisomerization of 11-cis-retinal to all-trans configuration occurs on the order of $200 \mathrm{fs}$ (Smith 2010).

For simulations of the squid structure, PDBid $2 \mathrm{Z73}$ was used along with the structure of 11-cis-retinal crystallized with it. For the S. punctatus structure, simulations were performed using 9-cis-retinal ligand in the lowest energy conformation. 9-cis-retinal was chosen based on the covalent docking screen results. Backbone atoms were kept rigid while binding pocket residues were made flexible. Trajectory visualization and RMSD analysis were accomplished using VMD (v1.9.1) (Humphrey, Dalke, \& Schulten, 1996). Potential energy of the system was summarized using the process_mdout.perl script, provided with the AMBER package. 
236

237

238

239

240

241

242

243

244

245

246

247

248

249

250

251

252

253

254

255

256

257

258

259

260

261

262

263

264

265

266

267

268

269

270

271

272

273

274

275

\section{Results}

Structural quality of homology model

For this study, a template-based model was constructed for the S. punctatus protein sequence using the I-TASSER website and GPCR specific database. Top Blastp hits of the $S$. punctatus protein to the PDB (as of 2016) include numerous opsin proteins, with the top scoring hit at $22.5 \%$ identity to a rhodopsin from Bos taurus (Table S1). Templates predicted by ITASSER included both chains of the T. pacificus rhodopsin protein (Table S2). The S. punctatus protein shares $22 \%$ sequence identity with the $T$. pacificus sequence and several key functional and structural motifs are conserved between the structures (Figure 1).

The binding pocket comprises a number of hydrophobic residues which provide a sterically restrictive space in which the retinal ligand is situated (orange). The major functional residues in this group are the conserved lysine (cyan) and counterion (red) which facilitate proton transfer during photoisomerization. The ionic lock motif contains an (E/D)RY and NPxxY motif, which together act as a structural support which stabilizes the protein in the inactive ("dark") state, and is broken upon receptor activation (Smith 2010). In S. punctatus, the (E/D)RY and NPxxY motifs are both functionally conserved as 115ERY117 and 326NPVLF330 (pink). Two additional linkages are responsible for correct protein folding: a conserved disulfide bond between C110-C187, and a conserved salt bridge between R117-D190. S. punctatus model possesses both of these motifs as C91-C166 (yellow), and potentially R158-D169 (purple).

The quality of the $S$. punctatus homology model was assessed with Ramachandran plots (Ramachandran, Ramakrishnan, \& Sasisekharan, 1963), generated using PROCHECK (Laskowski et al., 1993; Wiederstein \& Sipp1, 2007), which graphically display the backbone dihedral angles ( $\varphi$ and $\psi$ ) of each amino acid residue in a protein. An aggregate assessment of observed protein structures determined by x-ray crystallography defines regions of acceptable stereochemistry; here using observed phi-psi distribution for 121,870 residues from 463 known $\mathrm{X}$-ray protein structures. In practice, this analysis can be used for structure validation. A model with more than $90 \%$ of its residues having favorable stereochemistry is considered to be of good quality. For S. punctatus, the percentage of residues which fell within the most favorable region was $85.4 \%$. The T. pacificus crystal structure of rhodopsin (Murakami 2008) has a score of $90.9 \%$ in this category (Figure S1).

Additionally, Verify3D (Lüthy, Bowie, \& Eisenberg, 1992) was used to assess model quality. Structures modeled correctly will have higher scores than structures which have been modeled incorrectly. Here, the $S$. punctatus model generated using the I-TASSER+GPCR database had a final score of 72.41 , and $46.32 \%$ of the residues had an averaged $3 \mathrm{D}-1 \mathrm{D}$ score $>=$ 0.2. For comparison, the rhodopsin x-ray crystal structure from $T$. pacificus had a final score of 87.85 , and $58.86 \%$ of residues had a profile score $>=0.2$. To provide further support that the $S$. punctatus model was constructed correctly, a model was generated with the S. punctatus sequence using the sensory rhodopsin II x-ray crystal structure from the archaeon Natronomonas pharaonis (PDBid 1H68, Royant et al., 2001), a type 1 opsin and thus a presumed incorrect 
276 modeling target. In this reconstruction, the final score was 15.08 , and only $19.57 \%$ of residues 277 had a Verify3D score $>=0.2$. When the scores for these proteins are plotted as a function of their 278 sequences (Figure S2) the average scores fall between - 0.12 and 0.66 (Figure S2B) and -0.19 and 2790.87 (Figure S2A). The average scores for the S. punctatus structure model constructed against $2801 \mathrm{H} 68$ however fall between -0.56 and 0.49 (Figure S2C).

281

282

283

284

285

286

287

288

289

290

291

292

293

294

295

296

297

298

299

300

301

302

303

304

305

306

307

308

309

310

311

312

313

314

315

Finally, ProQM (Ray, Lindahl, \& Wallner, 2010) was used to assess model quality, providing a score between 0 (poor) and 1 (correctly modeled). The $S$. punctatus model had a global quality score of 0.5 and a range of local quality scores 0.03 to 0.91 , with low scores corresponding to loop regions (Figure S3A). The T. pacificus crystal structure had in general higher local quality scores, with a range of 0.11 to 1.13 and a global quality score of 0.766 (Figure S3B). The quality assessment of the presumed mis-modeled S. punctatus homology model (described above) again suggested it was poorly modeled, with a global quality score of 0.42 and a range of local quality scores from -0.18 to 0.96 (Figure S3C).

\section{Computational ligand screen}

Rhodopsin functions through the use of a retinaldehyde chromophore. The most common chromophore observed in both invertebrates and vertebrates is 11-cis-retinal (Shichida \& Matsuyama, 2009). This retinal isomer is also used in the T. pacificus rhodopsin association. To determine if the S. punctatus rhodopsin utilized the same isomeric configuration of retinal, computational protein-ligand docking was performed using Autodock 4 with 11-cis-retinal and other vitamin-A based retinaldehyde compounds. The compounds 11-cis-retinal, all-transretinal, 9-cis-retinal, 13-cis-retinal, 3,4-dihydroretinal, 3-hydroxyretinal, and 4-hydroxyretinal were tested (Figure 2) and all have demonstrated activity in nature. When docked against the squid crystal structure, 11-cis-retinal had the lowest free energy of binding, as expected since this is the functional chromophore for the squid rhodopsin protein. Ranking the energy scores, alltrans-retinal had the highest free energy of binding. For the $S$. punctatus modeled structure, the lowest energy conformations were observed when bound to 9-cis-retinal isomer, with the next lowest conformations observed with the 11-cis-retinal isomer. The results of the initial preMolecular Dynamics (MD) docking screen are provided in Table 1.

To assess the flexibility of the predicted S. punctatus + 9-cis-retinal complex, molecular dynamics simulations on the opsin and unbound chromophore using AMBER 14 were performed and compared to that of the canonical squid + 11-cis-retinal complex. An overview of the potential energy of two systems during the 100ns simulation is given in Figure 3A. While the potential energy of the $S$. punctatus complex is much lower than that of the squid, both complexes are extremely stable over the long term. Using VMD to plot the RMSD relative to the averaged structure for both complexes also suggests they are stable. For both complexes, these results are given in Figure 3B. The RMSD of the squid complex begins around $1.5 \AA$ and ends close to $0.7 \AA$ during the simulation, with a mean and standard deviation of $0.87 \pm 0.21 \AA$. The $S$. punctatus complex fluctuates between $2.56 \AA$ and $8.92 \AA$, with a mean and standard deviation of $4.67 \pm 1.07 \AA$. Additionally, the per-residue RMSD for both structures remains low 
316 during the course of the simulation (Figure $3 \mathrm{~B}+\mathrm{C}$ ), with an increase corresponding to the c317 terminal loop of the fungal model.

318 The binding pockets of both receptor proteins were characterized using mdpocket in the 319 fpocket software package (http://fpocket.sourceforge.net) (Le Guilloux, Schmidtke, \& Tuffery, 320 2009; Schmidtke, et al., 2011). Fpocket generates clusters of spheres to describe pockets 321 identified in a given protein, while mdpocket allows for detection and visualization of pockets on 322 MD trajectories. The pockets predicted for the T. pacificus and S. punctatus MD trajectories are 323 displayed in Figure 4 A-B, outlined as both density (red) and frequency (blue) maps. The main 324 binding pockets of both structures can be found at low densities (isovalue of 3) and frequently (isovalue of 50\%) during the simulations. In the unbound state, the average of the distances from

326

327

328

329

330

331

332

333

334

335

336

337

338

339

340

341

342

343

344

345

346

347

348

349

350

351

352

353

354

355 the center of mass of the retinal ligand to each of the $\mathrm{C} \alpha$ of binding pocket residues in the $T$. pacificus or $S$. punctatus structures did not change substantially during the course of the simulation, though there is a slight increase and noticeably more variability in the S. punctatus pocket. (Figure 4E).

During the course of the $S$. punctatus simulation, the 9-cis-retinal ligand shifts approximately $1.6 \AA$ inside the binding pocket of the model. A shift of approximately $1.8 \AA$ by the functional nitrogen atom can be observed during the simulation. The ion lock distance (between E116 and R250) remained consistent, decreasing only slightly from $3.5 \AA$ to $3.4 \AA$, while the disulfide bond distance (cysteine - cysteine link between C91 and C166) decreased from 5.4A to $3.7 \AA$ (Figure 5). During the T. pacificus simulation, both the 11-cis-retinal ligand shift by less than $1 \AA$, and the conserved unbound lysine residue (K296) maintains its linear conformation. The $T$. pacificus ion lock and disulfide distances and orientations remained relatively unchanged, potentially due to the T. pacificus structure being closer to optimal conformation initially.

To assess any potential improvements in docking scores, revised covalent docking was performed using the structures resulting from the previously described simulations and the ligands presented in Figure 1. Table 1 provides the initial and revised measures of free energy for each docking run, and Table S2 provides energy terms of the ligands and all energy terms for each of the lowest docked runs. For S. punctatus the measures of free energy using the structures from the end of the simulation (frame 3) were lowest when using 13-cis and 9-cis isomers of retinal (-1.76 and $-1.83 \mathrm{kcal} / \mathrm{mol}$, respectively), with the 11-cis isomer as the next lowest $(-1.49$ $\mathrm{kcal} / \mathrm{mol}$ ). For $T$. pacificus all isomers were relatively similarly low-scoring, although with slight increases using models near the end of the simulation.

\section{Discussion}

Using the genomes of early-diverging chytrid fungi B. dendrobatidis and S. punctatus, we identified putative proteins homologous to metazoan Type 2 Rhodopsins. Rhodopsin functions as a photoreceptor via a well-defined interaction between a photon of light, a retinaldehyde chromophore (observed commonly as 11-cis-retinal), and the GPCR opsin protein in order to initiate a cellular response through intracellularly-coupled heterotrimeric G-proteins. There is evidence to suggest that the covalent bond architecture is not biochemically necessary in 
356

357

358

359

360

361

362

363

364

365

366

367

368

369

370

371

372

373

374

375

376

377

378

379

380

381

382

383

384

385

386

387

388

389

390

391

392

393

394

395

experimentally manipulated Type 1 opsins (Schweiger, Tittor, \& Oesterhelt, 1994). However, in naturally occurring opsins this interaction is always facilitated by the presence of a lysine residue in the binding pocket of the GPCR to which the chromophore is covalently bound (Smith 2010). Of the putative rhodopsin proteins identified in several chytrid fungi, the candidate identified in $S$. punctatus is the most likely to function as photoreceptor. This protein is highly similar to experimentally verified metazoan rhodopsin proteins and shares structural and functional motifs including most critically the conserved lysine residue within the binding pocket.

Experimental evidence in Blastocladiomycota chytrid fungi indicates they have light regulated behavior (Avelar et al. 2014). Phototaxis has been documented in A. reticulatus and the responsible photoreceptor protein was deduced to be rhodopsin (Saranak \& Foster, 1997). Additionally, in the entomopathogenic chytrid fungus Coelomomyces dodgei, photoperioddependent spore release has been documented, although the underlying biochemical pathway has not been clearly elucidated (Federici, 1983). The most comprehensive evidence that couples light response behavior and molecular mechanisms is in B. emersonii. Light perception in this fungus requires eye-spot localized photoreceptors that were determined to be fusion proteins of a type 1 rhodopsin and guanylyl cyclase (Avelar et al., 2014; Avelar et al., 2015). There is much less experimental evidence for rhodopsin-regulated behavior in Chytridiomycota. The primary observations are in Rhizophydium littoreum, for which there is evidence of blue-light responsive phototaxis (Muehlstein, Amon, \& Leffler, 1987), but the underlying molecular mechanisms have not been explored.

In the present study we used in silico docking screens to assess the capacity of the $S$. punctatus opsin model to bind to known retinal ligands in order to form a functional rhodopsin complex. This sequence is currently the only Type 2 rhodopsin identified in fungi which possesses the conserved lysine and counterion residues, though more complete genomic and transcriptomic sampling of zoosporic lineages will undoubtedly identify additional instances of this gene. Based on this screen, 9-cis-retinal appeared to be the most favorable ligand for use by S. punctatus. As such, the 9-cis isomer was used in subsequent refinement by molecular dynamics. When compared to the squid crystal structure and its canonical 11-cis-retinal ligand, the $S$. punctatus +9 -cis-retinal complex takes longer to reach a stable conformation, and this conformation deviates quite a bit from the initial structure model. While this suggests inconsistencies with the initial homology model, both the squid and $S$. punctatus opsin+chromophore complexes appear highly stable. Different chromophores have been observed in nature in opsin complexes being utilized for different purposes. While functional binding pocket residues (e.g. lysine and counterion) are conserved, there are binding pocket residue differences between the squid and fungal structures which could account for the utilization of different chromophores. For example, fewer large hydrophobic residues in the fungal pocket might permit accommodation of different chromophores. Additionally, during the course of exploring why 11-cis-retinal was most often observed in mammalian systems, Sekharan and Morokuma (2011) demonstrated that, generally, 9-cis-retinal is only slightly less stable, and under certain conditions can in fact be more stable, than the 11-cis isomer. Our 
396 molecular docking results suggest that one preferential ordering of ligands would be: 9-cis $>13$ 397 cis $>11$-cis $>$ 4-hydroxy $>$ all-trans $>3$,4-dihydro- $>3$-hydroxy-retinal. While a thorough 398 treatment of the phylogenetic support for the shared ancestry of these proteins will be presented 399 elsewhere (Medina EM, unpublished data), the functional relevance of such proteins remains to 400 be explored. The $S$. punctatus + 9-cis-retinal complex after molecular dynamics simulations 401 supports the hypothesis that this GPCR is a functional photoreceptor and provides a foundation 402 for future work dealing with photoreception in early diverging fungi.

403

404

405

\section{Acknowledgements}

406 We would like to thank Zhiye Tang and Christopher Roberts for technical assistance. Genome 407 sequence and gene annotations of the Spizellomyces punctatus, Allomyces macrogynus and 408 Batrachochytrium dendrobatidis JEL423 strains were obtained from the Broad Institute and the 409 Origins of Multicellularity Project. Genome of the Batrachochytrium dendrobatidis JAM81 410 strain was obtained from the Joint Genome Institute Mycocosm database. Computations were 411 performed on the University of California-Riverside Institute for Integrative Genome Biology 412 high performance bioinformatics cluster (http://www.bioinformatics.ucr.edu/). 


\section{References}

415 Ai R, Chang CE. Ligand-specific homology modeling of human cannabinoid (CB1) receptor.

416 2012. Journal of Molecular Graphics and Modelling. 38:155-164.

417 DOI:10.1016/j.jmgm.2012.05.002.

418

419

420

421

422

423

424

425

426

427

428

429

430

431

432

433

434

435

436

437

438

439

440

441

442

443

444

445

446

447

448

449

450

451

452

453

454

455

456

457

458

459
Armougom F, Moretti S, Poirot O, Audic S, Dumas P, Schaeli B, Keduas V, Notredame C. 2006. Expresso: automatic incorporation of structural information in multiple sequence alignments using 3D-Coffee. Nucleic Acids Research. 34:W604-8. DOI:10.1093/nar/gk1092.

Avelar GM, Schumacher RI, Zaini PA, Leonard G, Richards TA, Gomes SL. 2014. A

Rhodopsin-Guanylyl Cyclase Gene Fusion Functions in Visual Perception in a Fungus. Current Biology. 24:1234-1240. DOI:10.1016/j.cub.2014.04.009.

Avelar GM, Glaser T, Leonard G, Richards TA, Ulrich H, Gomes SL. 2015. A Cyclic GMPDependent $\mathrm{K}+$ Channel in the Blastocladiomycete Fungus Blastocladiella emersonii. Eukaryotic Cell. 14:958-963. DOI:10.1128/EC.00087-15.

Bashford D, Case DA. 2000. Generalized Born models of macromolecular solvation effects. Annual Review of Physical Chemistry. 51:129-152. DOI:10.1146/annurev.physchem.51.1.12.

Becker EA, Yao AI, Seitzer PM, Kind T, Wang T, Eigenheer R, Shao KSY, Yarov-Yarovoy V, Facciotti MT. 2016. A Large and Phylogenetically Diverse Class of Type 1 Opsins Lacking a Canonical Retinal Binding Site. PLoS One. 11:e0156543. DOI:10.1371/journal.pone.0156543.

Bermudez M, Wolber G. 2015. Structure versus function - The impact of computational methods on the discovery of specific GPCR-ligands. Bioorganic \& Medicinal Chemistry. 23:3907-3912. DOI:10.1016/j.bmc.2015.03.026.

Bradley P, Misura KMS, Baker D. 2005. Toward High-Resolution de Novo Structure Prediction for Small Proteins. Science. 309:1868-1871. DOI:10.1126/science.1113801.

Bolton EE, Wang Y, Thiessen PA, Bryant SH. 2008. PubChem: Integrated Platform of Small Molecules and Biological Activities. In: Wheeler RA, Spellmeyer DC, ed. Annual Reports in Computational Chemistry. Elsevier. 12:217-241. DOI:10.1016/S1574-1400(08)00012-1.

Case DA, Berryman JT, Betz RM, Cerutti DS, Cheatham III TE, Darden TA, Duke RE, Giese TJ, Gohlke H, Goetz AW, Homeyer N, Izadi S, Janowski P, Kaus J, Kovalenko A, Lee T, LeGrand S, Li P, Luchko T, Luo R, Madej B, Merz KM, Monard G, Needham P, Nguyen HT, Omelyan I, Onufriev A, Roe DR, Roitberg A, Salomon-Ferrer R, Simmerling CL, Smith W, Swails J, Walker RC, Wang J, Wolf RM, Wu X, York DM, Kollman PA. 2015. AMBER 2015. University of California, San Francisco. Available at http://ambermd.org/doc12/Amber15.pdf (accessed 18 July 2016)

Chung SY, Subbiah S. 1996. A structural explanation for the twilight zone of protein sequence homology. Structure. 4:1123-1127. DOI:10.1016/S0969-2126(96)00119-0. 
460 Devine EL, Theobald DL, Oprian DD. 2016. Relocating the Active-Site Lysine in Rhodopsin: 2. 461 Evolutionary Intermediates. Biochemistry. DOI:10.1021/acs.biochem.6b00478.

462

463

464

465

466

467

468

469

470

471

472

473

474

475

476

477

478

479

480

481

482

483

484

485

486

487

488

489

490

491

492

493

494

495

496

497

498

499

500

501

502

503

504

505
Edgar RC, Drive RM, Valley M. 2004. MUSCLE: multiple sequence alignment with high accuracy and high throughput. Nucleic Acids Research. 32:1792-1797.

DOI:10.1093/nar/gkh340.

Eddy SR. 2011. Accelerated Profile HMM Searches. PLoS Computational Biology. 7:e1002195. DOI:10.1371/journal.pcbi.1002195.

Eswar N, Webb B, Marti-Renom MA, Madhusudhan MS, Eramian D, Shen M-Y, Pieper U, Sali A. 2007. Comparative protein structure modeling using MODELLER. In: Coligan JE, Dunn BM, Speicher DW \&Wingfield PT, ed. Current Protocols in Protein Science. John Wiley \& Sons, Inc, Unit 2.9. DOI:10.1002/0471140864.ps0209s50.

Federici BA. 1983. Species-specific gating of gametangial dehiscence as a temporal reproductive isolating mechanism in Coelomomyces. Proceedings of the National Academy of Sciences USA. 80:604-607.

Finn RD, Bateman A, Clements J, Coggill P, Eberhardt RY, Eddy SR, Heger A, Hetherington K, Holm L, Mistry J, Sonnhammer EL, Tate J, Punta M. 2014. Pfam: the protein families database. Nucleic Acids Research. 42:D222-30. DOI:10.1093/nar/gkt1223.

Hanwell MD, Curtis DE, Lonie DC, Vandermeersch T, Zurek E, Hutchison GR. 2012. Avogadro: an advanced semantic chemical editor, visualization, and analysis platform. Journal of Cheminformatics. 4:17. DOI:10.1186/1758-2946-4-17.

Hornak V, Abel R, Okur A, Strockbine B, Roitberg A, Simmerling C. 2006. Comparison of multiple Amber force fields and development of improved protein backbone parameters.

Proteins. 65:712-725. DOI:10.1002/prot.21123.

Humphrey W, Dalke A, Schulten K. 1996. VMD: visual molecular dynamics. Journal of Molecular Graphics. 14:33-38. DOI:10.1016/0263-7855(96)00018-5.

Idnurm A, Verma S, Corrochano LM. 2010. A glimpse into the basis of vision in the kingdom Mycota. Fungal Genetics and Biology. 47:881-892. DOI:10.1016/j.fgb.2010.04.009.

James TY, Kauff F, Schoch CL, Matheny PB, Hofstetter V, Cox CJ, Celio G, Gueidan C, Fraker E, Miądlikowska J, Lumbsch HT, Rauhut A, Reeb V, Arnold AE, Amtoft A, Stajich JE, Hosaka K, Sung, G-H, Johnson D, O'Rourke B, Crockett M, Binder M, Curtis JM, Slot, JC, Wang Z, Wilson, AW, Schüssler A, Longcore JE, O'Donnell K, Mozley-Standridge SE, Porter D, Letcher PM, Powell MJ, Taylor JW, White MM, Griffith GW, Davies DR, Humber RA, Morton JB, Sugiyama J, Rossman AY, Rogers JD, Pfister DH, Hewitt D, Hansen K, Hambleton S, Shoemaker RA, Kohlmeyer J, Volkmann-Kohlmeyer B, Spotts RA, Serdani M, Crous PW, Hughes KW, Matsuura K, Langer E, Langer G, Untereiner WA, Lücking R, Büdel B, Geiser DM, Aptroot A, Diederich P, Schmitt I, Schultz M, Yahr R, Hibbett DS, Lutzoni F, McLaughlin 
506 DJ, Spatafora JW, Vilgalys R. 2006. Reconstructing the early evolution of Fungi using a six507 gene phylogeny. Nature. 443:818-822. DOI:10.1038/nature05110.

508

509

510

511

512

513

514

515

516

517

518

519

520

521

522

523

524

525

526

527

528

529

530

531

532

533

534

535

536

537

538

539

540

541

542

543

544

545

546

547

548

549

550

551

James TY, Pelin A, Bonen L, Ahrendt S, Sain D, Corradi N, Stajich JE. 2013. Shared signatures of parasitism and phylogenomics unite Cryptomycota and Microsporidia. Current Biology. 23:1548-1553. DOI:10.1016/j.cub.2013.06.057.

Jones MDM, Forn I, Gadelha C, Egan MJ, Bass D, Massana R, Richards, TA. 2011. Discovery of novel intermediate forms redefines the fungal tree of life. Nature. 474:200-203.

DOI:10.1038/nature09984.

Katoh K, Kuma K-I, Toh H, Miyata T. 2005. MAFFT version 5: improvement in accuracy of multiple sequence alignment. Nucleic Acids Research. 33:511-518. DOI:10.1093/nar/gki198.

Katoh K, Misawa K, Kuma K-I, Miyata T. 2002. MAFFT: a novel method for rapid multiple sequence alignment based on fast Fourier transform. Nucleic Acids Research. 30: 3059-3066. DOI:10.1093/nar/gkf436.

Katritch V, Cherezov V, Stevens RC. 2013. Structure-Function of the G Protein-Coupled Receptor Superfamily. Annual Review of Pharmacology and Toxicology. 53:531-556. DOI:10.1146/annurev-pharmtox-032112-135923.

Krishnan A, Almén MS, Fredriksson R, Schiöth HB. The origin of GPCRs: identification of mammalian like Rhodopsin, Adhesion, Glutamate and Frizzled GPCRs in fungi. PLoS One. 7:e29817. DOI:10.1371/journal.pone.0029817.

Lagerström MC, Schiöth HB. 2008. Structural diversity of G protein-coupled receptors and significance for drug discovery. Nature Reviews Drug Discovery. 7:339-357.

DOI: $10.1038 / \mathrm{nrd} 2518$.

Laskowski RA, MacArthur MW, Moss DS, Thornton JM. 1993. PROCHECK: a program to check the stereochemical quality of protein structures. Journal of Applied Crystallography. 26: 283-291. DOI:10.1107/S002188989200994.

Le Guilloux V, Schmidtke P, Tuffery P. 2009. Fpocket: an open source platform for ligand pocket detection. BMC Bioinformatics. 10:168. DOI:10.1186/1471-2105-10-168.

Lu M, Dousis AD, Ma J. 2008. OPUS-Rota: a fast and accurate method for side-chain modeling. Protein Science. 17:1576-1585. DOI:10.1110/ps.035022.108.

Lüthy R, Bowie JU, Eisenberg D. 1992. Assessment of protein models with three-dimensional profiles. Nature. 356:83-85. DOI:10.1038/356083a0.

Morris GM, Huey R, Lindstrom W, Sanner MF, Belew RK, Goodsell DS, Olson AJ. 2009. AutoDock4 and AutoDockTools4: Automated Docking with Selective Receptor Flexibility. Journal of Computational Chemistry. 30:2785-2791. DOI:10.1002/jcc.21256.AutoDock4. 
552

553

554

555

556

557

558

559

560

561

562

563

564

565

566

567

568

569

570

571

572

573

574

575

576

577

578

579

580

581

582

583

584

585

586

587

588

589

590

591

592

593

594

595

596

597
Muehlstein LK, Amon JP, Leffler DL. 1987. Phototaxis in the Marine Fungus Rhizophydium littoreum. Applied Environmental Microbiology. 53:1668-1672.

Murakami M, Kouyama T. 2008. Crystal structure of squid rhodopsin. Nature. 453:363-367. DOI:10.1038/nature06925.

Neves SR, Ram PT, Iyengar R. 2002. G protein pathways. Science. 296:1636-1639.

DOI:10.1126/science. 1071550 .

Notredame C, Higgins DG, Heringa J. 2000. T-Coffee: A novel method for fast and accurate multiple sequence alignment. Journal of Molecular Biology. 302:205-217.

DOI:10.1006/jmbi.2000.4042.

Onufriev A, Bashford D, David A. 2000. Modification of the generalized Born model suitable for macromolecules. Journal of Physical Chemistry B. 104:3712-3720. DOI:10.1021/jp994072s.

Ray A, Lindahl E, Wallner B. 2010. Model quality assessment for membrane proteins.

Bioinformatics. 26:3067-3074. DOI:10.1093/bioinformatics/btq581.

Ramachandran GN, Ramakrishnan C, Sasisekharan V. 1963. Stereochemistry of polypeptide chain configurations. Journal of Molecular Biology. 7:95-99.

Royant A, Nollert P, Edman K, Neutze R, Landau EM, Pebay-Peyroula E, Navarro J. 2001. $\mathrm{X}$-ray structure of sensory rhodopsin II at 2.1-Å resolution. Proceedings of the National Academy of Sciences USA. 98:10131-10136. DOI:10.1073/pnas.181203898.

Sali A. 1995. Modeling mutations and homologous proteins. Current Opinion in Biotechnology. 6:437-451. DOI:10.1016/0958-1669(95)80074-3.

Saranak J, Foster KW. 1997. Rhodopsin guides fungal phototaxis. Nature. 387:465-466. DOI:10.1038/387465a0.

Schmidtke P, Bidon-Chanal A, Luque J, Barril X. 2011. MDpocket: Open source cavity detection and characterization on molecular dynamics trajectories. Bioinformatics. 27:32763285. DOI:10.1093/bioinformatics/btr550.

Schweiger U, Tittor J, Oesterhelt D. 1994. Bacteriorhodopsin can function without a covalent linkage between retinal and protein. Biochemistry. 33:535-541.

Sekharan S, Morokuma K. 2011. Why 11-cis-Retinal? Why Not 7-cis, 9-cis, or 13-cis-Retinal in the Eye? Journal of the American Chemical Society. 133:19052-19055. DOI:10.1021/ja208789h.

Shen M-Y, Sali A. 2006. Statistical potential for assessment and prediction of protein structures. Protein Science. 15:2507-2524. DOI:10.1110/ps.062416606. 
598 Shichida Y, Matsuyama T. 2009. Evolution of opsins and phototransduction. Philosophical

599 Transactions of the Royal Society B: Biological Sciences. 364: 2881-2895.

600 DOI:10.1098/rstb.2009.0051.

601

602

603

604

605

606

607

608

609

Slater GS, Birney E. 2005. Automated generation of heuristics for biological sequence comparison. BMC Bioinformatics. 6:31-41. DOI:10.1186/1471-2105-6-31.

Smith SO. 2010. Structure and activation of the visual pigment rhodopsin. Annual Review of Biophysics. 2010;39: 309-328. DOI:10.1146/annurev-biophys-101209-104901.

Spudich JL, Yang CS, Jung KH, Spudich EN. 2000. Retinylidene proteins: structures and

610

611

612

613

614

615

616

617

618

619

620

621

622

623

624

625

626

627

628

629

630

631

632

633

634 functions from archaea to humans. Annual Review of Cell and Developmental Biology. 16:365392. DOI:10.1146/annurev.cellbio.16.1.365.

Stajich JE, Berbee ML, Blackwell M, Hibbett DS, James TY, Spatafora JW, Taylor JW. 2009. The Fungi. Current Biology. 19:R840-5. DOI:10.1016/j.cub.2009.07.004.

Taddese B, Simpson LM, Wall ID, Blaney FE, Reynolds CA. 2013. Modeling Active GPCR Conformations. In: Conn PM, ed. Methods in Enzymology. Academic Press. 2:21-35. DOI:10.1016/B978-0-12-407865-9.00002-9.

Terakita A. 2005. The opsins. Genome Biology. 6:213. DOI:10.1186/gb-2005-6-3-213.

Wang J, Wolf RM, Caldwell JW, Kollman PA, Case DA. 2004. Development and testing of a general amber force field. Journal of Computational Chemistry. 25:1157-1174.

DOI:10.1002/jcc.20035.

Wiederstein M, Sippl MJ. 2007. ProSA-web: interactive web service for the recognition of errors in three-dimensional structures of proteins. Nucleic Acids Research. 35:W407-10. DOI:10.1093/nar/gkm290.

Zhang F, Vierock J, Yizhar O, Fenno LE, Tsunoda S, Kianianmomeni A, Prigge M, Berndt A, Cushman J, Polle J, Magnuson J, Hegemann P, Deisseroth K. The microbial opsin family of optogenetic tools. Cell. 147:1446-1457. DOI:10.1016/j.cell.2011.12.004

Zhang J, Zhang Y. 2010. GPCRRD: G protein-coupled receptor spatial restraint database for 3D structure modeling and function annotation. Bioinformatics. 23:3004-5. DOI:

635 10.1093/bioinformatics/btq563 
Figure 1 (on next page)

Structural details of the S. punctatus homology model.

A) Structural alignment of S. punctatus homology model (grey) with T. pacificus crystal structure (light purple). S. punctatus residues are colored according to function: orange (binding pocket residues), red (putative counterion), purple (disulfide bond), yellow (salt bridge), dark blue (NPXXY motif), and pink \& black (ion lock). Inset figures provide details for structural alignments of $S$. punctatus and $T$. pacificus B) disulfide bond and salt bridge regions, C) binding pocket residues, and D) ERY and NPXXY regions. 


\section{PeerJ}

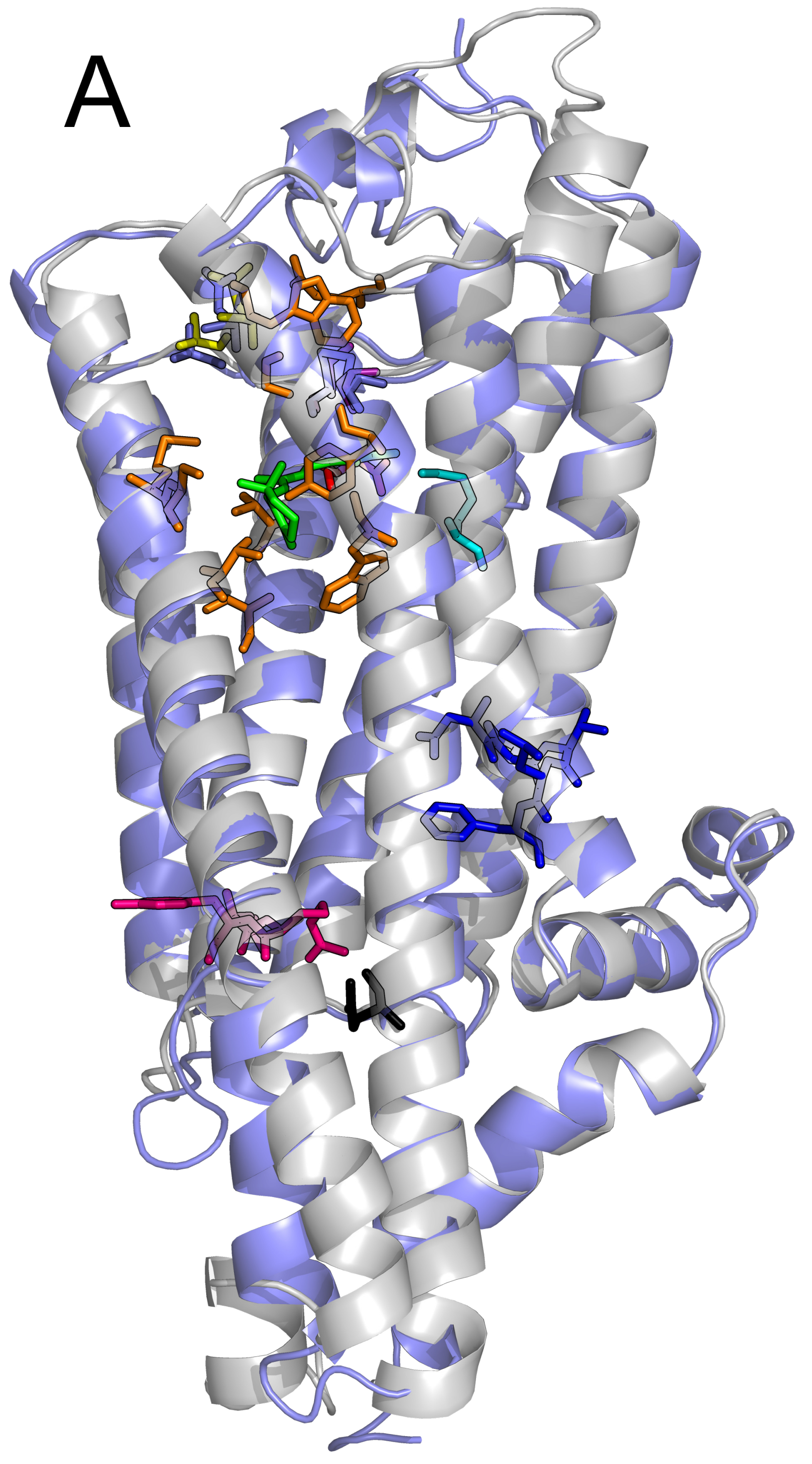

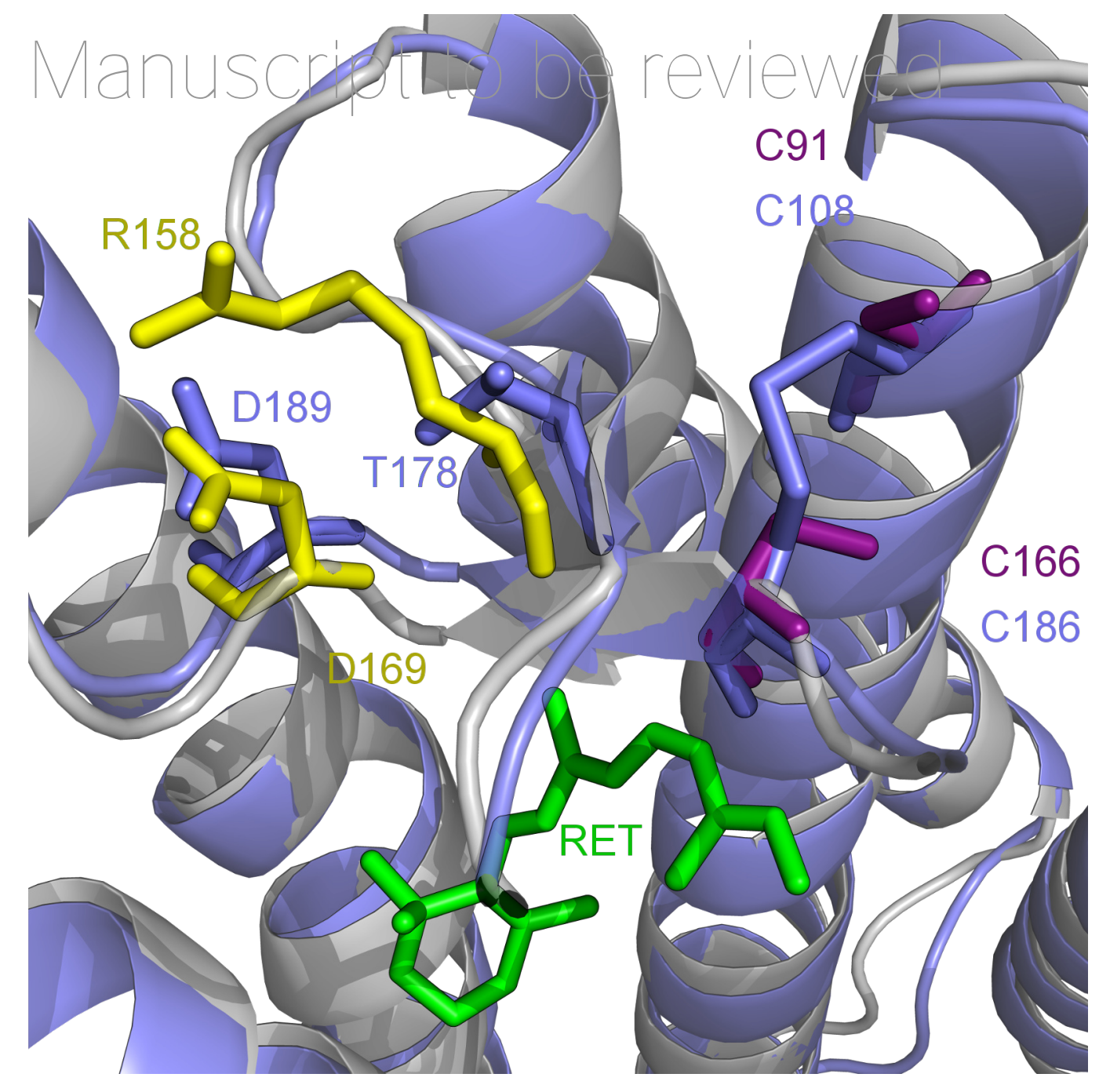
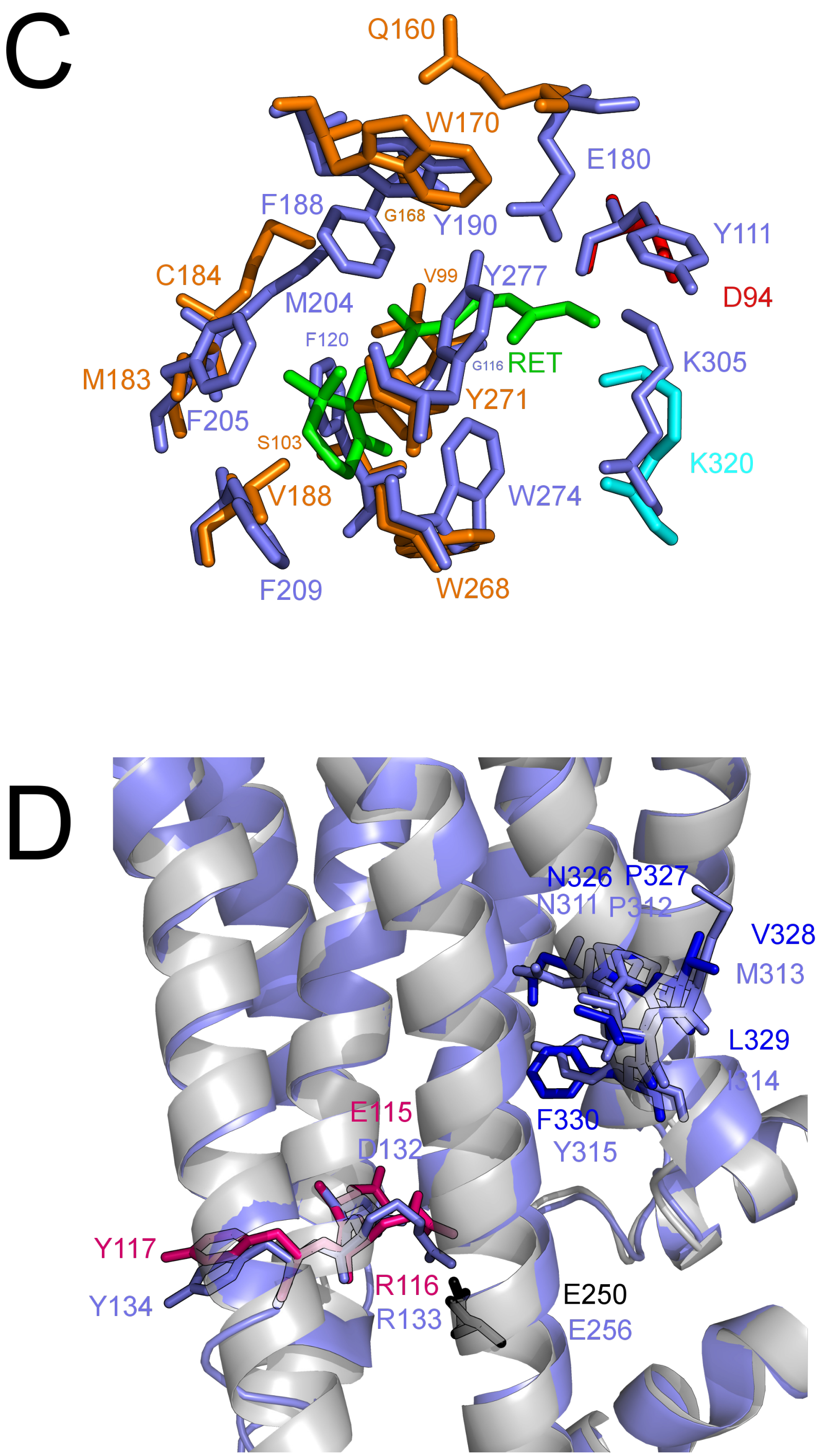


\section{Figure 2}

Retinaldehyde chromophores used by opsins.

Each of these isomers was used in an in silico docking screen against the $S$. punctatus homology model and the T. pacificus rhodopsin crystal structure (PDBID 2Z73). A) 9-cisretinal B) 11-cis-retinal C) 13-cis-retinal D) all-trans-retinal E) 3,4-dihydro-retinal F) 3hydroxyretinal G) 4-hydroxyretinal 
(c)

B<smiles>CC1=C(/C=C/C(C)=C/C=C\C(C)=C\C=O)C(C)(C)CCC1</smiles>

C<smiles>CC1=C(/C=C/C(C)=C/C=C/C(C)=C\C=O)C(C)(C)CCC1</smiles>

D<smiles>CC1=C(/C=C/C(C)=C/C=C/C(C)=C/C=O)C(C)(C)CCC1</smiles>

E<smiles>[CaH][GeH2]</smiles>

$\mathbf{F}$<smiles>CC1=C(/C=C/C(C)=C/C=C\C(C)=C\C=O)C(C)(C)CC(O)C1</smiles>

G

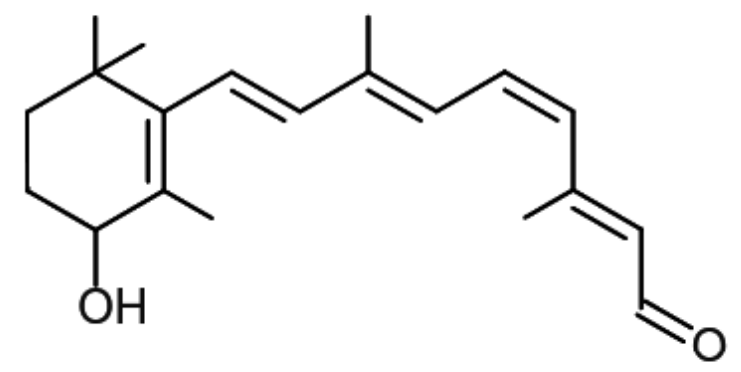




\section{Figure 3}

Overview plots of MD simulation runs of squid crystal structure with 11-cis-retinal (purple) and S. punctatus model with 9-cis-retinal (gray).

A) Demonstration that the average RMSD of the fungal structure is higher and more variable than that of the squid, but both are relatively stable during the simulation. $B+C$ ) Average root mean square deviation for each residue position during the 100 ns simulation for $S$. punctatus model and T. pacificus crystal structure, respectively. Helical regions are annotated with rectangles.
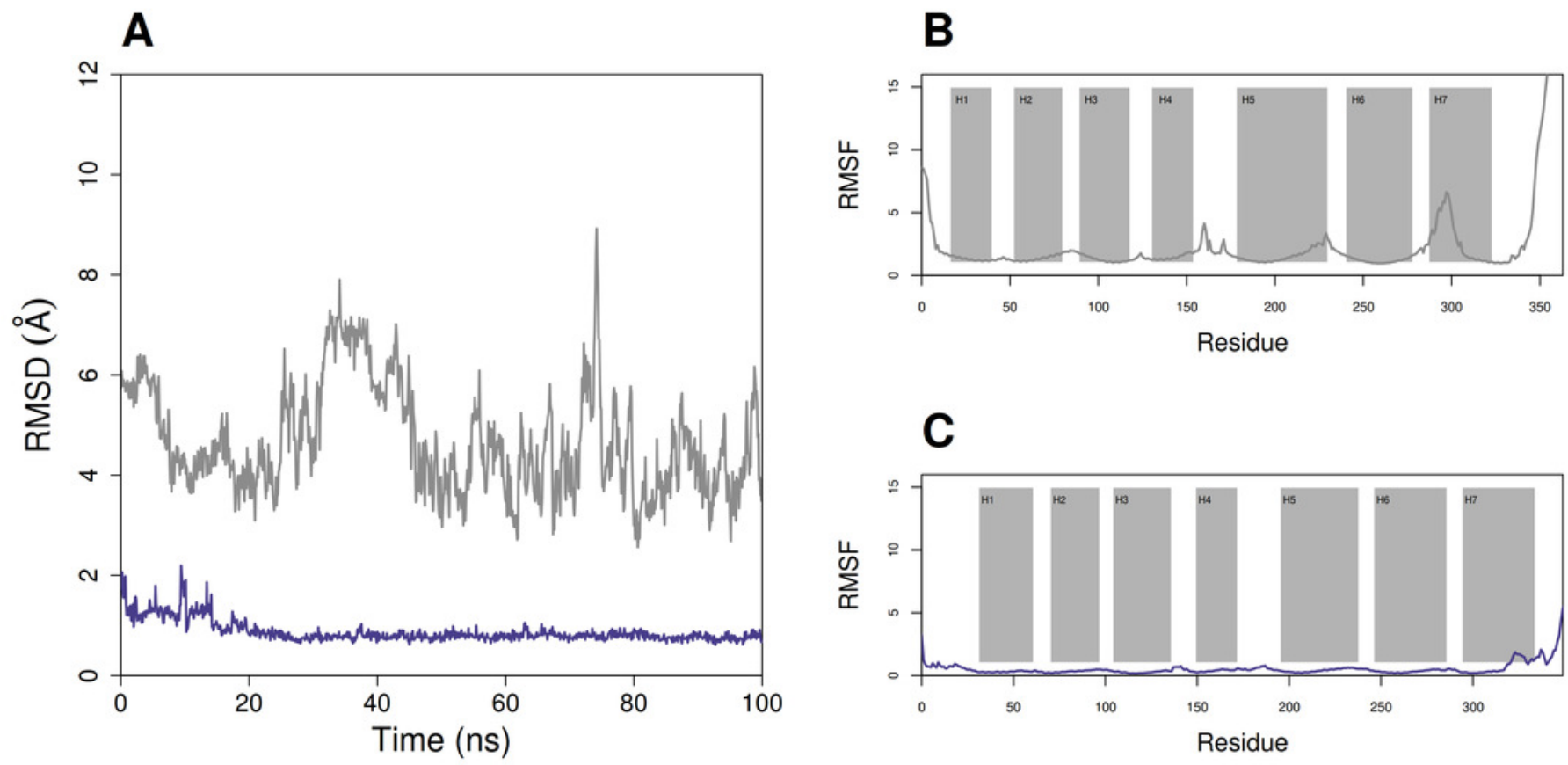


\section{Figure 4}

Demonstration of the changes in receptor binding pockets of $T$. pacificus and $S$. punctatus structures during MD simulations.

Receptor binding pockets of A) S. punctatus and B) T. pacificus structures during MD simulations as predicted by mdpocket (part of the Fpocket package). A density map (red; low isocontour value of 3 ) is provided, showing the relative enclosure of the binding site. A frequency map (blue; isovalue of 0.5 ) demonstrates the amount of time $(50 \%)$ that this pocket was found during the $100 \mathrm{~ns}$ MD simulation. The conserved lysine residue is represented in cyan, while the retinal ligand is given in green. C) Average distance between the retinal ligand center-of-mass and each of the binding pocket residues, as measured in both $T$. pacificus crystal structure (purple) and S. punctatus homology model (gray) over the course of the 100 ns molecular dynamics simulation. 

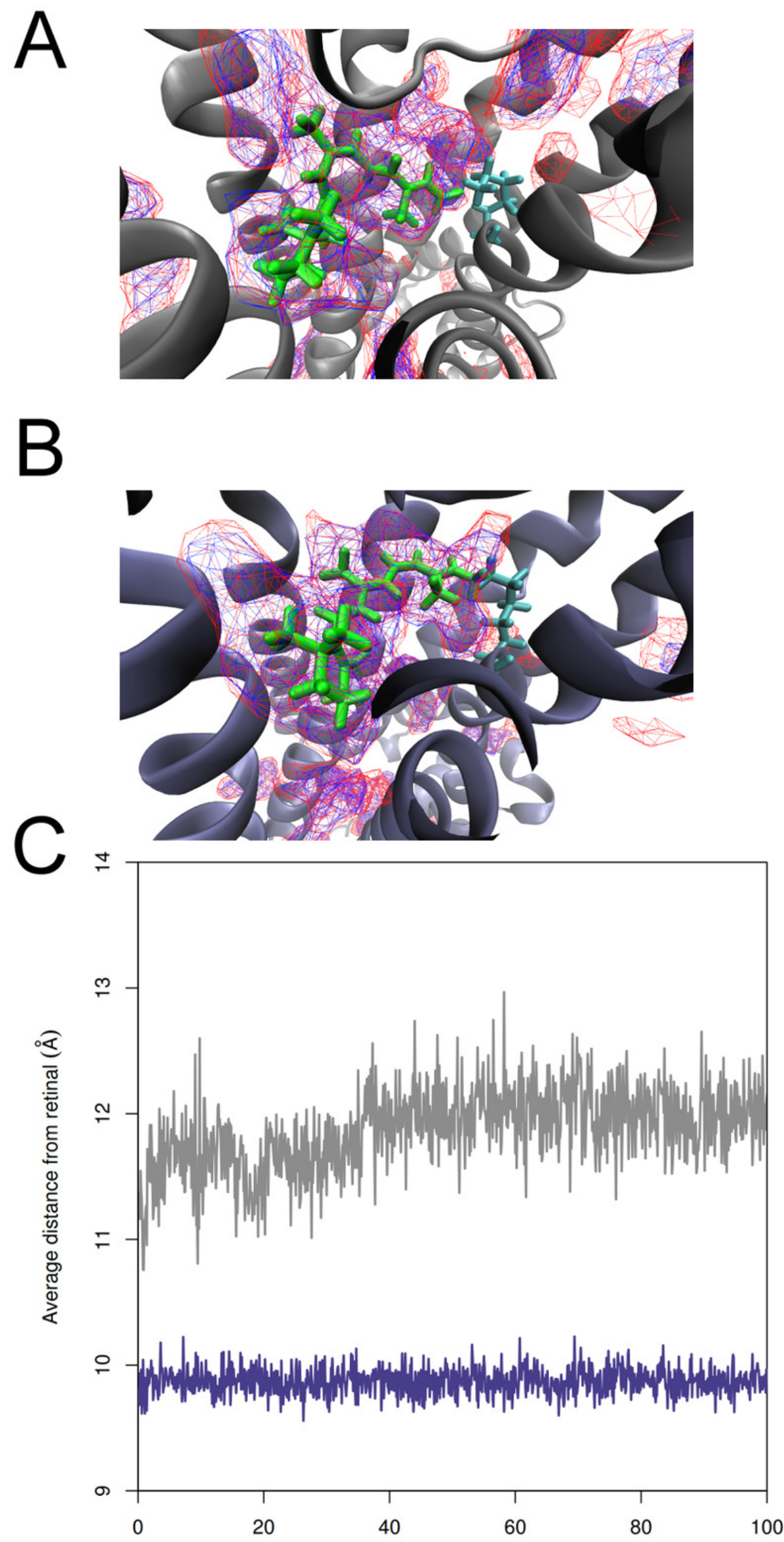


\section{Figure 5}

Change in distances between the features in the model of $S$. punctatus during $100 \mathrm{~ns}$ MD simulation.

A) cysteine-cysteine disulfide bond and B) ion lock structural motifs during the S. punctatus 100 ns MD simulation. Initial structural conformations are represented in dark blue with residue designations of "a". Final conformations are represented in cyan with residue designations of " $\mathrm{b}$ ". The distances are plotted over the duration of the simulation in C) and D) for cysteine-cysteine and ion lock, respectively. 


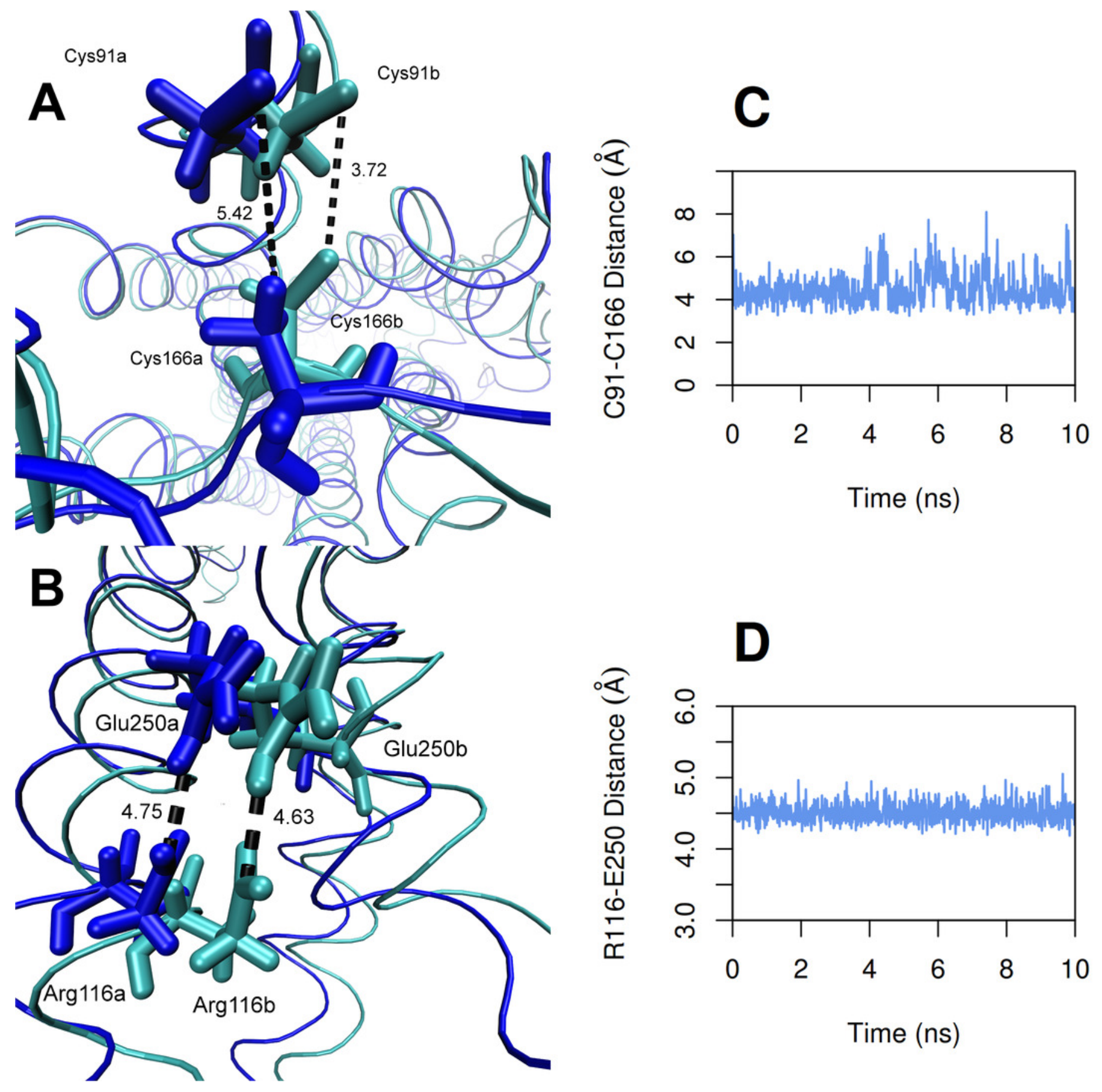




\section{Table $\mathbf{1}$ (on next page)}

Autodock results (binding energies in $\mathrm{kcal} / \mathrm{mol}$ ) for the $S$. punctatus homology model and T. pacificus crystal structure (PDB ID: 2Z73) with retinal isomers before and after molecular mechanics simulations.

Values represent free energy of the lowest scoring conformation (in $\mathrm{kcal} / \mathrm{mol}$ ). "State 0" refers to the model state prior to the start of MD simulations. States "1", "2", "3", and "4" refer to snapshot states immediately after start of MD, and at every 25 ns thereafter. During the course of the simulation, the free energy of binding is minimized for both the 13-cis- and 9-cis-retinal isomers with the S. punctatus homology model. For T. pacificus, State 0 represents the experimentally verified crystal structure, published in complex with 11-cisretinal (Murakami \& Kouyama 2008). 


\begin{tabular}{|l|l|l|l|l|l|l|l|}
\hline S. punctatus & 13-cis-retinal & 9-cis-retinal & $\begin{array}{l}\text { 3,4-dehydro- } \\
\text { retinal }\end{array}$ & $\begin{array}{l}\text { 3-hydroxy- } \\
\text { retinal }\end{array}$ & $\begin{array}{l}\text { 4-hydroxy- } \\
\text { retinal }\end{array}$ & $\begin{array}{l}\text { all-trans- } \\
\text { retinal }\end{array}$ & $\begin{array}{l}\text { 11-cis- } \\
\text { retinal }\end{array}$ \\
\hline State 0 & 24.52 & 6.77 & 24.06 & 24.23 & 24.81 & 23.44 & 10.07 \\
\hline State 1 & 0.31 & -1.56 & -2.02 & -1.37 & -1.30 & -1.78 & -0.68 \\
\hline State 2 & -1.96 & -2.72 & -2.15 & -2.31 & -2.58 & -2.41 & -1.78 \\
\hline State 3 & -2.11 & -0.35 & 0.43 & 0.20 & 0.47 & 0.42 & -2.11 \\
\hline State 4 & -1.76 & -1.83 & -0.82 & -0.48 & -1.15 & -1.03 & -1.49 \\
\hline T. pacificus & 13 -cis-retinal & $9-$ cis-retinal & $\begin{array}{l}3,4 \text {-dehydro- } \\
\text { retinal }\end{array}$ & $\begin{array}{l}\text { 3-hydroxy- } \\
\text { retinal }\end{array}$ & $\begin{array}{l}4 \text {-hydroxy- } \\
\text { retinal }\end{array}$ & $\begin{array}{l}\text { all-trans- } \\
\text { retinal }\end{array}$ & $\begin{array}{l}11-c i s- \\
\text { retinal }\end{array}$ \\
\hline State 0 & -2.83 & -5.43 & -4.52 & -2.94 & -3.20 & -4.83 & -5.66 \\
\hline State 1 & -0.91 & -3.84 & -3.66 & -3.40 & -3.30 & -3.78 & -1.88 \\
\hline State 2 & -4.57 & -2.25 & -4.74 & -4.24 & -4.40 & -4.73 & -4.17 \\
\hline State 3 & -3.79 & -2.43 & -2.82 & -1.95 & -2.56 & -2.87 & -3.52 \\
\hline State 4 & 0.27 & -0.80 & -1.04 & -0.69 & -0.75 & -1.02 & -0.21 \\
\hline
\end{tabular}

